\title{
O Futuro de Soft Robotics: Uma Revisão Bibliográfica
}

\section{Paulo Roberto Carvalho dos Santos ${ }^{1}$, Guilherme Henrique Alves da Silva ${ }^{1}$, Juliana Saragiotto Silva ${ }^{1}$}

\author{
${ }^{1}$ Instituto Federal do Mato Grosso (IFMT) \\ paulorobcss@gmail.com, guilhermehenriquee9@gmail.com, \\ juliana.silva@cba.ifmt.edu.br
}

\begin{abstract}
Soft robots are robots that, by the fact of being soft and not being limited by its axis, are able to perform movements beyond rigid robots. Thus, this work's objective is to present a literary revision about soft robots, seeking to explain a new theme which has potential of great impact in the future. The small number of researches about these robots point the difficulties found in this area, mainly in the research of sensors and materials to be used in their construction.

Resumo. Os soft robots são robôs que, pelo fato de serem moles e não estarem limitados pelos seus eixos, podem realizar movimentos além daqueles possíveis pelos robôs rígidos. Assim, o objetivo deste trabalho é apresentar uma revisão da literatura sobre os soft robots, buscando explicar um tema novo que possui um potencial de grande impacto no futuro. O reduzido número de pesquisas sobre esses robôs aponta as dificuldades encontradas nessa área, principalmente na pesquisa dos sensores e materiais a serem utilizados em sua construção.
\end{abstract}

\section{Introdução}

A robótica mole, ou soft robotics, busca a semelhança de movimentação dos animais e, por isso, possui a mesma capacidade de força de um robô rígido, mas com flexibilidade semelhante à de um polvo. Com a possibilidade de deformação do corpo dos robôs moles [LASCHI et al. 2016], obtém-se uma melhor interação entre a máquina e o ambiente [LASCHI e CIANCHETTI 2014], maior segurança para a interação com humanos e a possibilidade de, teoricamente, infinitos graus de liberdade (eixos para a movimentação) [POLYGERINOS et. al. 2017].

Referindo-se a esses robôs, o termo "mole" pode ser relacionado, principalmente, com a textura, com o fato de serem compostos de materiais deformáveis, elásticos ou ambos e de possuírem uma sensação familiar, quase natural ao toque humano [LASCHI e CIANCHETTI 2014]. Por mais que a redução da força e do tamanho dessas ferramentas ainda seja um desafio, os soft robots oferecem um futuro promissor, principalmente na área médica por meio do controle remoto de garras compostas de um material mole e flexível [ONGARO et al. 2016].

Face ao exposto, o objetivo deste artigo é apresentar uma revisão da literatura sobre os soft robots na perspectiva de abordar um tema recente. Desta forma, este artigo está estruturado em 5 seções, incluindo esta introdução. A seção 2 apresenta a metodologia utilizada no desenvolvimento do artigo. Na sequencia, a seção 3 descreve o referencial teórico empregado no decorrer da pesquisa. Logo após, a seção 4 busca relatar o resultado 
retirado da análise. Por fim, a última seção, busca apresentar as conclusões dos autores acerca do tema.

\section{Material e Métodos}

Esta pesquisa caracteriza-se como um estudo exploratório e bibliográfico, reunindo informações dos artigos selecionados com o objetivo de fornecer uma visão geral do tema, apresentando as possibilidades que podem ser alcançadas partindo do avanço da pesquisa dos robôs moles.

O desenvolvimento desta revisão bibliográfica compreendeu as seguintes etapas: (i) busca e seleção dos artigos; (ii) compreensão das principais ideias dos artigos; (iii) comparação das ideias dos artigos selecionados, e; (iv) pesquisa de aplicações na atualidade.

Para a realização desta pesquisa foram utilizadas como apoio as ferramentas de busca Google Acadêmico e ResearchGate, a partir das seguintes palavras-chave: "Soft Robotics"; "Robótica" e "Healthcare". O mapeamento dos trabalhos baseou-se em artigos publicados entre os anos de 1981 e 2018. Além disso, o critério para a inclusão dos artigos foi o fato de possuírem uma explicação mais detalhada sobre o funcionamento dos robôs e uma apresentação mais ampla da aplicação destes robôs na área médica.

\section{Conceitos Básicos}

Esta seção se dedica a explanar alguns conceitos basilares acerca do tema "soft robotics".

\subsection{Robótica}

A robótica envolve um universo amplo em classificação de robôs - os quais possuem várias definições, dentre as quais a mais utilizada é a descrita na ISO 8373:2012 (ISO, 2012), que "define termos usados em relação aos robôs e aparelhos robóticos operando em ambos ambientes industriais e não industriais"; assim, o robô é classificado como um "manipulador multipropósito controlado automaticamente, reprogramável, programável em três ou mais eixos, que pode ser fixo no lugar ou móvel, de uso em aplicações industriais”.

Além disso, é importante mencionar que os robôs já não são apenas usados na indústria na forma de braços robóticos, em função de inovações tecnológicas, que levaram ao surgimento de novos tipos de robôs - como descrito na próxima seção.

\subsection{Soft Robos - Robôs moles}

Para a construção dos soft robots são utilizados materiais flexíveis, que podem ser moldados de acordo com a necessidade, alcançando, assim, maior segurança no processo de interação dos robôs com o ambiente e com os humanos [LASCHI e CIANCHETTI, 2014], [POLYGERINOS et al. 2017]. Esses materiais podem ser ligas metálicas com memória de forma (shape memory alloys, SMAs), polímeros com memória de forma (shape memory polymers, SMPs) ou polímeros eletroativos (eletroactive polymers, EAPs).

A busca pela evolução dos soft robots se deve ao fato desses robôs possuírem, por exemplo, a reabilitação de membros e a possibilidade de novos instrumentos cirúrgicos 
[POLYGERINOS et al. 2017]. Diante disso, foram observados os benefícios da utilização dos robôs, que são abordados a seguir.

\section{Resultados e Discussão}

Partindo das informações adquiridas durante essa revisão bibliográfica, notou-se que o desenvolvimento de robôs moles trará diversos benefícios. A vantagem do uso desses robôs em comparação aos robôs rígidos está na possibilidade de uma movimentação mais fluida e com menor impacto no ambiente ao seu redor, proporcionando maior segurança para a interação humana com os robôs. Outro benefício identificado foi o baixo custo dos robôs e sua baixa complexidade [POLYGERINOS et al. 2017].

Ademais, observou-se que existem limitações no desenvolvimento dos soft robots, como na geração de torque e força exatos por meio da pressão e nos sensores pequenos, maleáveis e precisos [LIDA e LASCHI 2011]. Para a movimentação e aplicação da pressão pelo robô, são encontradas dificuldades ao analisar qual o melhor fluido a ser utilizado em cada caso [POLYGERINOS et al. 2017].

\section{Conclusão}

Esta revisão da literatura teve por objetivo apresentar os soft robots, observando seus princípios de funcionamento e os materiais que utilizado em sua fabricação. Embora tenha sido observado um número reduzido de pesquisas nesta área, a partir deste trabalho, foi possível notar que este tipo de robô ainda é utilizado de forma incipiente, embora exista um grande potencial de aplicação na reabilitação de movimentos em humanos e em cirurgias médicas. Há a intenção de, futuramente, desenvolver um robô mole, tendo como característica ser semelhante a um braço robótico, sendo movimentado por líquido.

\section{Referências}

Laschi, C. e Cianchetti, M. (2014) "Soft robotics: new perspectives for robot bodyware and control", Em: frontiers in Bioengineering and Biotechnology, p. 1-5, janeiro.

Laschi, C., Mazzolai, B. e Cianchetti, M. (2016) "Soft robotics: Technologies and systems pushing the boundaries of robot abilities", Em: Science Robotics, v. 1, n. 1, p. 1-11, dezembro.

Polygerinos, P., Correll, N., Morin, S. A., Modasegh, B., Onal, C. D., Petersen, K., Cianchetti, M., Tolley, M. T. e Shepherd, R. F. (2017) "Soft Robotics: Review of FluidDriven Intrinsically Soft Devices; Manufacturing, Sensing, Control, and Applications in Human-Robot Interaction", Em: Advanced Engineering Materials, v. 19, n. 12, p. 1-22, dezembro.

Ongaro, F., Pacchierotti, C., Yoon, C., Prattichizzo, D., Gracias, D. H., Misra, S. (2016), "Evaluation of an electromagnetic system with haptic feedback for control of untethered, soft grippers affected by disturbances", Em: $6^{\text {th }}$ IEEE International Conference on Biomedical Robotics and Biomechatronics, Cingapura, 26-29 de junho.

Lida, F., Laschi, C. (2011) "Soft Robotics: Challenges and Perspectives", Em: Procedia Computer Science, v. 7, p. 99-102.
ISO 8373.
(2012)
"Robots
and
robotic
devices", https://www.iso.org/obp/ui/\#iso:std:iso:8373:ed-2:v1:en 